Article

\title{
Global Trends in Seasonality of Normalized Difference Vegetation Index (NDVI), 1982-2011
}

\section{J. Ronald Eastman ${ }^{1,2, *, \dagger}$, Florencia Sangermano ${ }^{1,2, \uparrow}$, Elia A. Machado ${ }^{3, \dagger}$, John Rogan ${ }^{2}$ and Assaf Anyamba ${ }^{4}$}

1 Clark Labs, Clark University, 950 Main Street, Worcester, MA 01610, USA;

E-Mail: fsangermano@clarku.edu

2 Graduate School of Geography, Clark University, 950 Main Street, Worcester, MA 01610, USA; E-Mail: jrogan@clarku.edu

3 Department of Earth, Environmental, and Geospatial Sciences, Lehman College, City University of New York, NY 10468, USA; E-Mail: elia.machado@lehman.cuny.edu

4 GESTAR/USRA \& Biospheric Sciences Laboratory, NASA Goddard Space Flight Center, Greenbelt, MD 20771,USA; E-Mail: assaf.anyamba@nasa.gov

$\dagger$ These authors contributed equally to this work.

* Author to whom correspondence should be addressed; E-Mail: reastman@clarku.edu; Tel.: +1-508-793-7526; Fax: +1-508-793-8842.

Received: 8 July 2013; in revised form: 20 September 2013 / Accepted: 23 September 2013 / Published: 30 September 2013

Abstract: A 30-year series of global monthly Normalized Difference Vegetation Index (NDVI) imagery derived from the Global Inventory Modeling and Mapping Studies (GIMMS) NDVI3g archive was analyzed for the presence of trends in changing seasonality. Using the Seasonal Trend Analysis (STA) procedure, over half $(56.30 \%)$ of land surfaces were found to exhibit significant trends. Almost half $(46.10 \%)$ of the significant trends belonged to three classes of seasonal trends (or changes). Class 1 consisted of areas that experienced a uniform increase in NDVI throughout the year, and was primarily associated with forested areas, particularly broadleaf forests. Class 2 consisted of areas experiencing an increase in the amplitude of the annual seasonal signal whereby increases in NDVI in the green season were balanced by decreases in the brown season. These areas were found primarily in grassland and shrubland regions. Class 3 was found primarily in the Taiga and Tundra biomes and exhibited increases in the annual summer peak in NDVI. While no single attribution of cause could be determined for each 
of these classes, it was evident that they are primarily found in natural areas (as opposed to anthropogenic land cover conversions) and that they are consistent with climate-related ameliorations of growing conditions during the study period.

Keywords: NDVI; GIMMS NDVI3g; Seasonal Trend Analysis; AVHRR; phenology

\section{Introduction}

In recent decades considerable interest has been focused on trends in vegetation phenology. Part of this interest derives from the possibility of using the phenological response of vegetation as an indicator of climate change given the sensitivity of vegetation dynamics to climate variables [1-3]. For instance, there is increasing evidence associating vegetation phenological changes, particularly the earlier flowering of plants in Europe and North America, with warmer temperatures during the last 30 years [4-7]. Another important reason is that changes in vegetation phenology have implications for the survival of species whose patterns of behavior are intricately synchronized to it [8] such as pollinators [7,9] and bird species whose reproductive success depends on timing their reproductive cycle with the peaks of food abundance [10,11]. Field measurements of vegetation phenology are labor intensive. Thus it has been logical to turn to the use of remote sensing instruments on earth observation satellite platforms for phenological measurements. The most well-known example is the use of the Normalized Difference Vegetation Index (NDVI) derived from measurements of the optical reflectance of sunlight in the red and near-infrared wavelengths $[12,13]$. However, the resolution of satellite-borne remotely sensed imagery is such that picture elements (pixels) commonly represent multiple land covers. In addition, remote sensing instruments sense electromagnetic energy that has travelled through the atmosphere. Thus, the seasonal character of vegetation index measurements over time may exhibit trends that represent changes in land cover and viewing conditions (such as changes in the presence of water vapor and aerosols) as well as true phenological responses. Consequently, it is more accurate to state that such studies are concerned with trends in the seasonality of NDVI. NDVI has been shown to be very sensitive to ecosystem conditions [14-16], particularly when paired with maximum value compositing to reduce the effects of atmospheric contaminants, such as clouds and aerosols [17]. Therefore it is of considerable value as an indicator of environmental change.

The longest image time series of NDVI that has been produced is the archive developed by the Global Inventory Modeling and Mapping Studies (GIMMS) group at NASA's Goddard Space Flight Center from the Advanced Very High Resolution Radiometer (AVHRR) instruments on the National Oceanic and Atmospheric Administration (NOAA) Polar Operational Environmental Satellite (POES) series. This global archive has now been processed to yield a 30 calendar year record (1981-2011) with a spatial resolution of $1 / 12^{\circ}$ (approximately $8 \mathrm{~km}$ at the equator) and a bi-weekly temporal resolution. In this paper we examine trends in the seasonality of NDVI using this archive and a recently-introduced analytical procedure known as Seasonal Trend Analysis (STA) [18]. Additionally, we introduce a means of classifying significant trends.

The purpose of this paper is to document the nature, prevalence and biome distribution of trends in the seasonality of NDVI. While numerous studies have examined trends in NDVI using earlier 
archives and phenological measurements such as SOS (start of season) or the length of the growing or active season (see for example [3,19-22]), this study is novel in its goal to classify trends in changes in seasonality and to establish their relative global frequency of occurrence over the past 30 years. As will be demonstrated, significant trends in the seasonality of NDVI are dominated by a very small number of highly prevalent trend types that have a preferred biome distribution.

\section{Data}

The primary data set used in this analysis is the new GIMMS NDVI version 3 (referred to as NDVI3g). This data set is a reconstructed extension of the previous version $[23,24]$. It comprises NDVI measurements derived from seven NOAA instruments $(7,9,11,14,16,17,18)$, which have been processed using an adaptive Empirical Mode Decomposition (EMD) [23]. This technique is used to identify and remove artifacts from the NDVI time series including solar zenith angle, trends associated with orbital drift, inconsistencies in the AVHRR data among sensors due to differences in sensor characteristics, and other extraneous factors that introduce nonlinear and non-stationary effects on the data. NDVI3g constitutes a 30-year long term data record (LTDR) and is the first dataset of its kind which is appropriate for long term studies of land surface trends in vegetation, seasonality and coupling between climate variability and vegetation over the last three decades.

As a preliminary step, the archive was modified by collapsing the bi-weekly NDVI data to monthly composites using maximum value compositing in order to further reduce cloud contamination and enhance the vegetation signal [17]. The resulting monthly composites were then projected to a Mollweide equal area projection to facilitate the correct calculation of areas. The monthly images from January 1982 to December 2011 were then selected for analysis (a 30 year record of monthly NDVI). This will be referred to in subsequent discussions simply as the NDVI data set.

The NDVI3g archive already has certain areas masked from consideration because they do not contain vegetation, or measurements are ambiguous due to surface conditions [25]. These include oceans, major lakes, the Greenland icecap, many parts of Arctic regions and Antarctica. In addition, we masked out areas where the mean annual NDVI was less than or equal to 0.15 on the basis that these are extremely arid or correspond to bare or desert regions in which trends may represent variations as much in soil characteristics as they do in vegetation [26-30]. Collectively, all unmasked areas will be referred to as land areas with an NDVI $>0.15$.

The second dataset used in the analysis was a global mapping of the world's biomes produced by the World Wildlife Fund [31]. The intention was to provide a basis for understanding the geographic and climatic distribution of seasonal trends. The map was reprojected to a Mollweide equal area projection and rasterized to match the dimensions of the NDVI archive.

Because we were concerned that the seasonal trends analyzed might relate to anthropogenic land cover change, we also needed a means of determining those areas that had undergone substantial modification. For this we used the GlobCover 2009 dataset [32]. GlobCover is a European Space Agency and partners initiative to produce global land cover maps. The 2009 map is based on $300 \mathrm{~m}$ resolution data from the MERIS sensor on ENVISAT for the period January-December 2009. The classification follows the United Nations Land Cover Classification System (LCCS), which is more focused on canopy structure than climate. Therefore, we judged it to be less suitable to our larger 
purposes. However, the mapping of anthropogenically altered landscapes in GlobCover 2009 was of special value to this study. Because the areas mapped as anthropogenically altered come near the end of the time period considered in this study, we reasoned that if seasonality trends were associated with anthropogenic land cover change, they would be very likely to be shown as anthropogenically altered in this map.

To make the map comparable, we reprojected the GlobCover 2009 map to a Mollweide equal area projection and assigned to each $8 \mathrm{~km}$ pixel in the output the predominant class among its corresponding $300 \mathrm{~m}$ pixels in the original. We subsequently reclassified the Globcover 2009 into two classes: anthropogenic land use and natural land cover. The anthropogenic class included: "Post-flooding or irrigated croplands (or aquatic)", "Rain-fed croplands", "Mosaic cropland (50\%-70\%)/vegetation (grassland/shrubland/forest) 20\%-50\%", and "Artificial surfaces and associated areas (Urban areas $>50 \%$ )", with an average reported accuracy of $91 \%$ [32]. The natural land cover class included all other natural and semi-natural terrestrial and aquatic vegetation land cover classes. The resulting map was then crosstabulated with the biome map [31] to yield two subcategories for each biome class-anthropogenic and natural. This modified biome map will subsequently be referred to simply as the BIOME data set.

\section{Methodology}

\subsection{Seasonal Trends Analysis}

The analytical procedure used in this study is known as Seasonal Trend Analysis (STA) and is based on a two-stage time series analysis [18]. The intention of the technique is to describe trends in the essential character of the seasonal cycle while rejecting noise and short-term variability. The first stage is similar to a Windowed Fourier Analysis [33] in which a separate harmonic regression is run on each year of imagery to extract the amplitude and phase of sine waves with an annual and semi-annual frequency along with the mean annual NDVI (the intercept term, also known as Amplitude 0). By using only the first two harmonics, the analysis discards high frequency variation such as that introduced by noise and short-term climate variability such as the Madden-Julian Oscillation [34]. This first stage thus yields five shape parameters to describe each seasonal cycle-Amplitude 0 (the mean annual signal), Amplitude 1 and Phase 1 (the annual cycle), and Amplitude 2 and Phase 2 (the semi-annual cycle). Since the analysis is conducted separately at each pixel, the result is in the form of five shape parameter images for each year. In aggregate, then, the first stage yields five time series, one for each shape parameter over the full length of the multi-year series considered.

In the second stage of the STA, a Theil-Sen median slope is calculated over time at each pixel for each of the five shape parameter time series. Unlike the slope of a linear regression, the median slope operator is a robust statistic that is highly resistant to noise [35] - up to $29 \%$ of the samples over time can be outliers without having any effect on the measured trend. In this case, since the samples are annual measures of shape characteristics, it can thus be assumed that short inter-annual disturbances (i.e., those 8 years or less in this case) such as individual El Niño/Southern Oscillation (ENSO) events, have little impact on the longer term trends represented by the median trends. As a result, the STA procedure rejects two types of noise: sub-annual noise with a frequency less than 6 months and 
inter-annual variability up to $29 \%$ of the length of the series. The technique thus focuses on a generalized characterization of long term trends in seasonality.

For visualization, color composites can be created from any set of three of the five parameter trend images by assigning them to the red, green and blue primary colors. Generally, the composite based on the three amplitudes (see Figure 1) carries the greatest amount of information [18]. However, in its implementation in the Earth Trends Modeler [36], a software system for the analysis of earth observation image time series, an interpretive aid is also provided that shows modeled curves for the start and the end of the series based on the intercepts and slopes of these five harmonic shape parameters. The curves in these diagrams are based on a description of only two harmonics (involving five parameters, including Amplitude 0), and therefore, they represent generalizations of the curves, much as a regression line generalizes the linear relationship between two variables.

Figure 1. Global mapping of seasonal trends in Normalized Difference Vegetation Index (NDVI), 1982-2011. This color composite expresses trends in Amplitude 0 (mean annual NDVI) in red, trends in Amplitude 1 (annual cycle) in green and trends in Amplitude 2 (semi-annual cycle) in blue. Areas in light gray have been masked because their mean NDVI is less than 0.15. Areas in dark gray have no significant trend. All other colored areas on land characterize trends that are significant at the $p<0.01$ level for one or more of the Seasonal Trend Analysis (STA) shape parameters using the Contextual Mann Kendall (CMK) test of trend significance. Thus areas that are bright magenta, for example, are experiencing significantly increasing trends in Amplitude 0 and Amplitude 2.

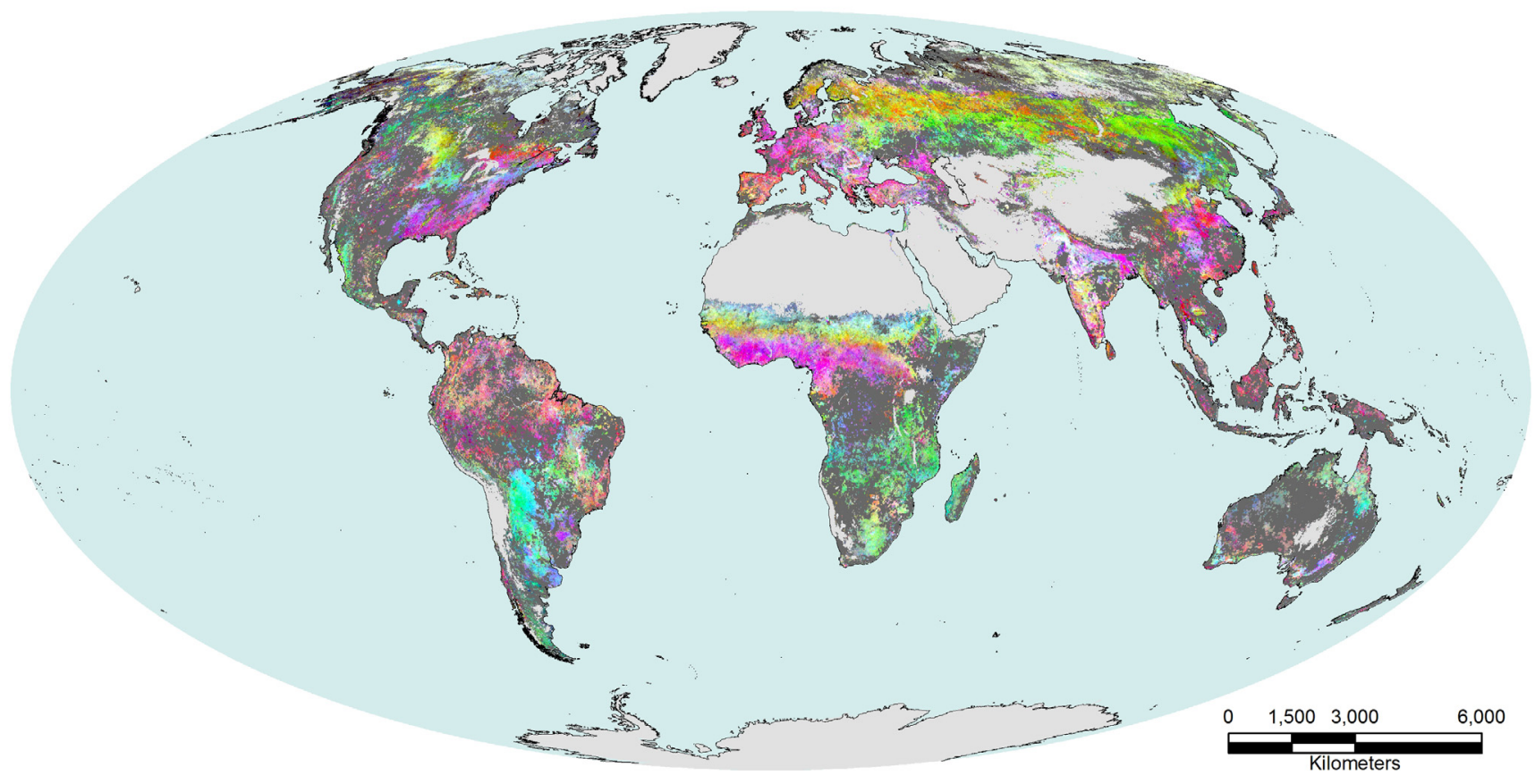

\subsection{Relationship of Seasonal Trends to Phenological Measurements}

Phenological measurements are focused on the timing of significant biological events. As such, they are useful in the planning of agricultural activities, pest management and ecological studies [37,38]. Typical phenological parameters include SOS (start of season), EOS (end of season), and length of the 
growing season as the difference between these [39]. However, there has been considerable variability in how to measure these parameters. For example, for SOS, ground measurements have included anthesis/middle bloom, first flower bud, first flowers expanding, first inflorescence, first leaf, full leaf expansion, leaf budburst or budbreak, and $75 \%$ of full leaf expansion [3], among others. With remotely sensed imagery, the measurement becomes even more challenging given the inability to unambiguously observe specific events. Thus SOS measures using remotely sensed image products such as NDVI have included various thresholds, derivatives, smoothing functions, model fits and spectral decompositions [39]. In addition, the attempt to measure phenological events using remotely sensed imagery has been particularly challenging due to cloud contamination, variable atmospheric conditions and noise. As a consequence, there has been considerable variability in reported results with respect to phenological trends [3].

Given the difficulty of identifying specific phenological events with remotely sensed imagery, STA was developed as an attempt to describe seasonal curves in their totality rather than to identify specific events along their development, and especially, to detect trends in their transformation. The measured characteristics (the amplitudes and phases) are not intended to function as phenological measurements, but rather, to serve as efficient shape parameters for the description of the character and dynamics of seasonal curves. In typical use, the color mapping of parameters is used to identify regions of common trend while the interactive legend tool provides a description of the curve and its transformation over time. However, for the purposes of this study, we have added a procedure for the identification and categorization of significant trends as will be described below.

Given this understanding of the very different intent of STA from traditional phenological analyses, it should be recognized that there is some correspondence between the STA parameters and traditional phenological measurements. Using NDVI as an example, Amplitude 0 (i.e., the mean annual NDVI), corresponds to annual integrated NDVI rescaled to a mean value. As such, it would be expected to correlate strongly with annual gross primary productivity [40,41] and annual daytime flux of $\mathrm{CO}_{2}[42]$. Amplitude 1 is effectively the difference between the minimum and maximum NDVI values over the year with minor variations smoothed out, and expresses the annual range of NDVI. Phase 1 is similar to the Seasonal Shift Index [43] and expresses, as implemented in the Earth Trends Modeler [36], the angular position of the start of the cycle (January). Thus, for example, most locations in the northern hemisphere mid-latitudes have a Phase 1 value near $270^{\circ}$ since January is at the lowest position on a sine wave. Amplitude 2 and Phase 2 are difficult to interpret. Nominally they represent the magnitude and position of a semi-annual curve. However, for most locations, the semi-annual component is primarily a modifier of the annual curve shape. For example, in polar regions the phenological curve is steeper than a sine wave. This type of curve can be achieved by adding a strong semi-annual component that steepens the annual sine wave. This underscores the fact that the Amplitude and Phase parameters in STA are not intended as freestanding phenological measurements. Rather, they are shape parameters that can describe generalizations of seasonal curves in the nature of splines. Additionally, it should be noted that the focus is on trends in these parameters, which imply transformations of seasonal curves from one shape to another. It is these transformations that are the focus of this study.

Using the NDVI data set, an STA analysis as described above, was run using the procedure available in the Earth Trends Modeler [36]. In the run, the option was chosen to calculate the significance of the trends in the five shape parameters using the Contextual Mann Kendall 
statistic [44]. The Contextual Mann Kendall (CMK) non-parametric statistic is a modified form of the Mann Kendall test of trend significance [45,46]. It calculates the Mann-Kendall statistic at each pixel along with its 8 neighboring pixels, and then combines the information from these nine pixels while correcting for autocorrelation over both space and time, providing a contextual assessment of trend significance. If a pixel exhibits a trend but its neighbors do not, then the confidence in that trend is reduced. Similarly, if the neighbors of a pixel are experiencing similar trends, then the confidence of that trend is increased. The technique is very effective in eliminating random noise and applies a very fundamental geographic principle to the assessment of trend - that areas close in space are expected to experience similar trends over time.

In order to categorize the seasonal trends, the CMK trend significance for each of the five shape parameters was classified into three categories: significantly increasing at the $p<0.01$ level, significantly decreasing at the $p<0.01$ level, and not significant. All combinations of these significance categories over the five shape parameter trends thus yield a total of $3^{5}=243$ seasonal trend classes. Of these, 242 represent significant trends in seasonality of one or more parameters and one represents a stable pattern. However, because each class is defined by a combination of five independent tests, the Bonferroni corrected probability level for the significant classes should really be considered as $p<0.05$ [47].

Once the major seasonal trend classes were isolated, their distribution within the BIOMES map was determined. By calculating the proportion of all pixels with an NDVI $>0.15$ that belonged to each seasonal trend class, it is possible to establish a confidence interval for the expected proportion within a specified confidence interval. For the purposes of this study, a $p<0.01$ confidence interval was established. Values outside of that confidence interval were designated as occurring more or less frequently than expected.

\section{Results}

There are 226 classes of significant changes (Figure S1, in the supporting information), that include different combinations of significant changes in Amplitude 0, Amplitude 1, Amplitude 2, Phase 1 and Phase 2. Figure 1 shows a color composite of all significant seasonal trends, with trends in Amplitude 0 rendered in red, trends in Amplitude 1 in green and trends in Amplitude 2 in blue, with a symmetric stretch around zero. What is striking is the magnitude of areas exhibiting significant trends. More than half $(56.30 \%)$ of all land areas with an NDVI $>0.15$ exhibit a significant trend in seasonality over the 30 year time period measured, producing a total of 226 significantly trending classes of seasonal curves. Thus a trending change in seasonality is not a rare occurrence. Further, significant trends are primarily associated with three major classes of seasonal trends. We therefore focus our attention on describing these three main classes of changes, which account for $46.10 \%$ of all significantly trending pixels. The first significant class (Class 1) accounts for $20.43 \%$ of all significantly trending areas, while the second (Class 2) and third (Class 3) most frequent classes account for $16.54 \%$ and $9.13 \%$ of all significantly trending areas, respectively. In addition, these three classes represent $25.95 \%$ of all land pixels with an NDVI $>0.15$. 
Class 1

Class 1 (Figure 2, shown in red, and Figure 3a) has an area of 11,755,525 $\mathrm{km}^{2}$ and describes $20.43 \%$ of all vegetated areas with a significant seasonal trend (accounting for $11.50 \%$ of all land surfaces with an NDVI $>0.15)$. This class represents areas with a significantly positive trend in Amplitude 0 (mean annual NDVI) and no significant change in any of the other four parameters (Amplitudes and Phases 1 and 2), producing curves that are raised uniformly throughout the year. Two examples of seasonal curves undergoing this trend are shown in Figures 4a,b.

Figure 2. The three most prevalent classes of significant seasonal trends in NDVI: Class 1 (red) shows significant increases in Amplitude 0 (Mean NDVI); Class 2 (blue) shows significant increases in Amplitude 1 (increase in the difference between minimum and maximum NDVI without affecting the mean); Class 3 (green) shows significant increases in Amplitude 0 and Amplitude 1 together.

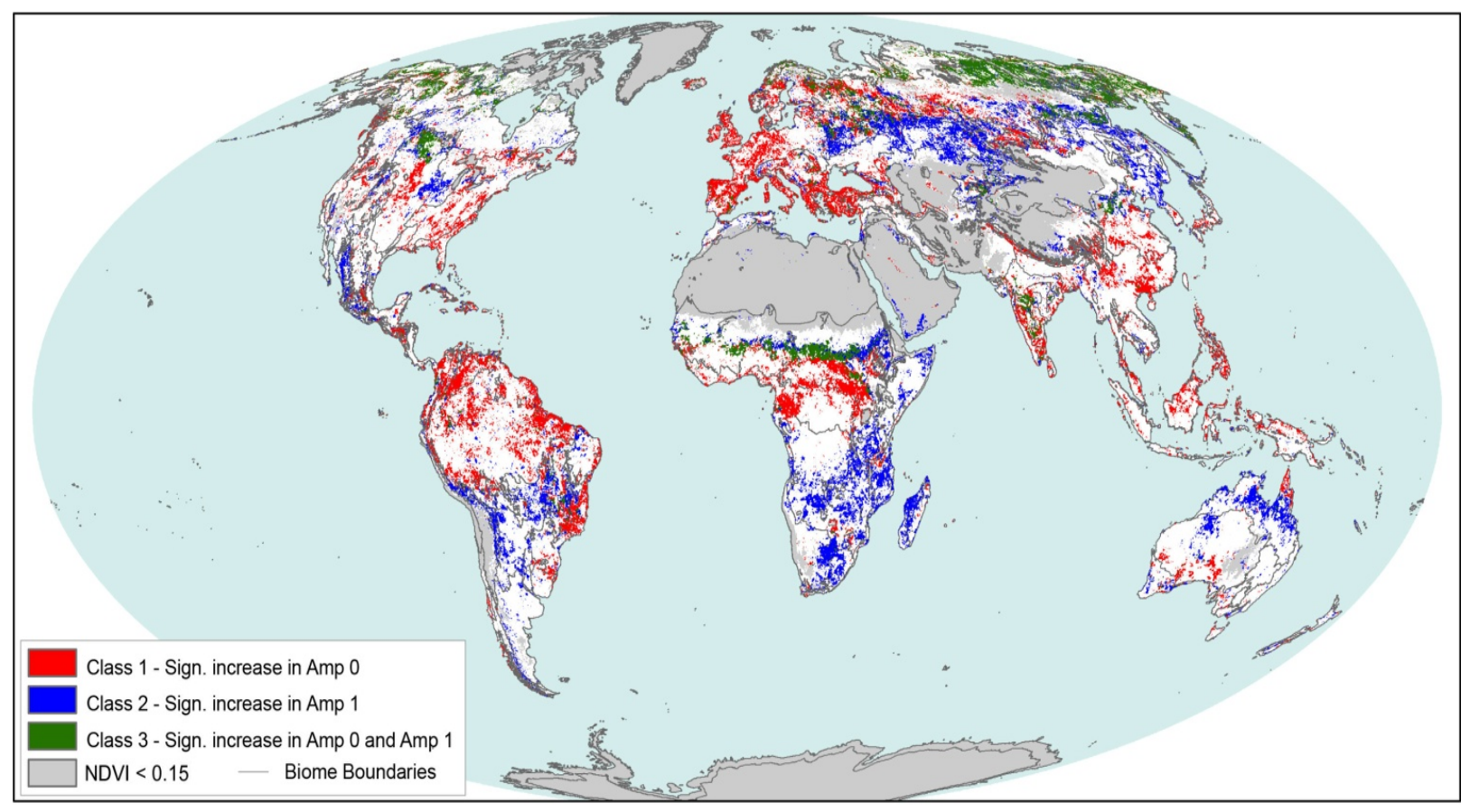

Class 1 is mostly associated with Forest Biomes as is evident from the histogram of its presence in each of the terrestrial biomes (Figure 3a). A chance distribution of this trend class among the biomes would imply an expected within-class frequency of $11.50 \% \pm 0.01 \%(p<0.01)$ within each class. The per cent of area in Class 1 in each of the Biomes "Temperate Coniferous Forest" (13.71\%), "Mangroves" (16.74\%), “Temperate Broadleaf Forest" (17.11\%), “Tropical and Subtropical Moist Broadleaf Forest" (18.84\%), and "Mediterranean Forest, Woodland and Shrubs" (25.98\%), is thus more than would be expected by chance. Further, the majority of Class 1 trending pixels (78.43\%) occur in areas of natural land covers (Figure 3a). Only the "Tropical and Subtropical Moist Broadleaf Forest" and "Mediterranean Forest, Woodland and Shrubs" biomes show substantial anthropogenic disturbance among Class 1 pixels.

Of particular note is the fact that all curves in this family imply an increase in annual integrated NDVI regardless of the specifics of the shape of the curve. From a baseline of the minimum NDVI at 
the beginning of the series, this also implies an increase in the length of the growing season, regardless of how SOS is measured. Additionally, it indicates an earlier start of green-up and a later start of green-down. Over the 30 year AVHRR NDVI record, it would thus appear that forested areas are experiencing a consistent increase in productivity throughout the year leading to a lengthening of the growing season.

Class 2

Class 2 (Figure 2, shown in blue, and Figure 3b) describes $16.54 \%$ of all significant trends. Covering an area of $9,516,582 \mathrm{~km}^{2}$, it represents $9.31 \%$ of all global vegetated areas. Class 2 includes areas that exhibit a significant increase in Amplitude 1 (the annual cycle), but no other significant trend parameters. Two examples drawn from this family are shown in Figure 4c,d. This class of seasonal trend exhibits a characteristic increase in NDVI during the growing season balanced by declines during the brown season in order to maintain the same mean NDVI (Amplitude 0). With regard to the biome distribution, Class 2 is almost the inverse of Class 1, and has a more pronounced association with grassland and shrubland biomes (Figure 3b). For this class, the expected frequency of occurrence across biomes at the $p<0.01$ level would be $9.31 \% \pm 0.01 \%$. The Biomes "Tropical and Subtropical Dry Broadleaf Forests" (11.78\%), "Tropical and Subtropical Coniferous Forests" (12.46\%), "Temperate Grasslands, Savannas and Shrublands" (13.10\%), "Tropical \& Subtropical Grasslands, Savannas \& Shrublands" (15.79\%), "Flooded Grasslands and Savannas" (16.74\%), and "Montane Grasslands and Shrublands" (18.01\%), are all above this threshold and therefore have a significantly larger than expected frequency of occurrence among Class 2 seasonal trends. $79.49 \%$ of the areas associated with a Class 2 seasonal trend correspond to natural class covers (Figure 3b) with anthropogenic covers only approaching a sizeable (but still subdominant) proportion in temperate biomes.

\section{Class 3}

Class 3 (Figure 2, shown in green, and Figure 3c), encompasses an area of 5,250,427 $\mathrm{km}^{2}$. It describes $9.13 \%$ of all significant seasonal trends and represents $5.14 \%$ of global vegetated areas. This class represents areas with significant increases in both Amplitude 0 and Amplitude 1. It is characterized by an increase in productivity during the growing season, with the brown season not being modified. Therefore the mean NDVI (Amplitude 0) across the year increases and the difference between the maximum and minimum NDVI (Amplitude 1) also increases (Figure 4e,f). A chance distribution of Class 3 trend pixels across Biomes would imply a distribution of $5.14 \% \pm 0.01 \%$ $(p<0.01)$. This type of seasonal change has a more prevalent than random effect on solely two biomes: "Boreal Forests/Taiga" (13.50\%) and "Tundra" (22.61\%). Unlike Class 1 and Class 2, the biomes affected by this class do not show anthropogenic disturbance $(<1 \%$, Figure $3 \mathrm{c})$. 
Figure 3. (a) Proportion of each biome affected by Class 1, both of natural (dark red) and anthropogenic (light red) origin. (b) Proportion of each biome affected by Class 2, both of natural (dark blue) and anthropogenic (light blue) origin. (c) Proportion of each biome affected by Class 3, both of natural (dark green) and anthropogenic (light green) origin.

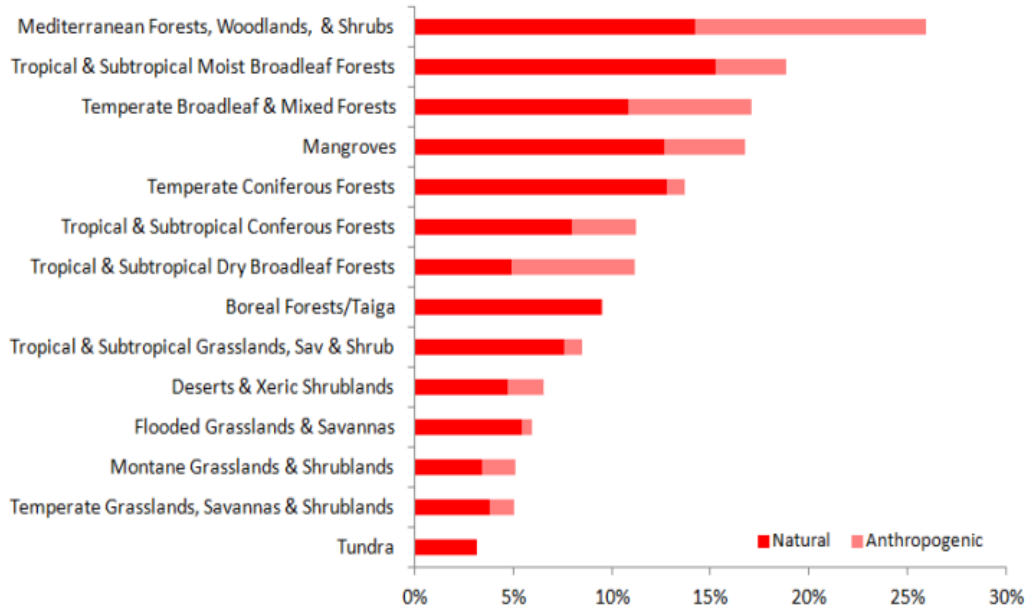

(a)

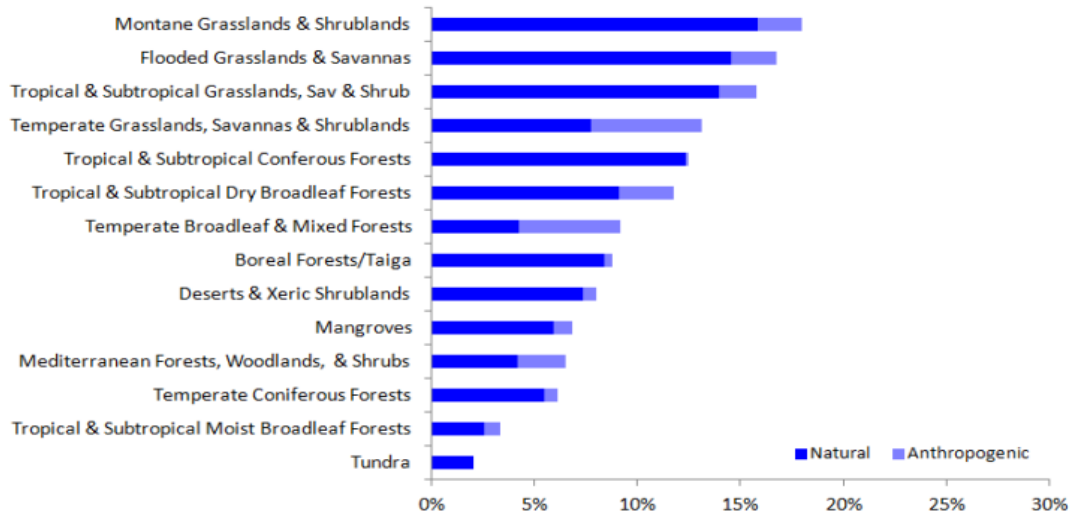

(b)

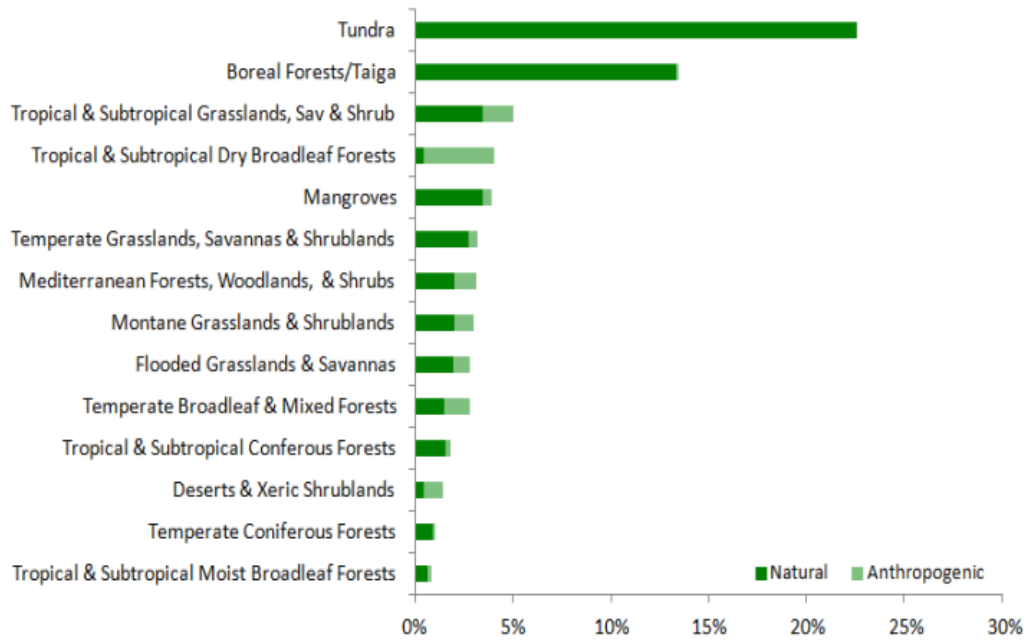

(c) 
Figure 4. Examples of seasonal trends representative of each of the three major trend classes from the 1982-2011 series. In each graph the X axis portrays the month of year while the Y axis represents NDVI x10,000. The green curve represents the characteristic seasonal curve at the beginning of the series while the red curve represents the characteristic seasonal curve at the end of the series. The difference between the two represents the change resulting from the trend. (Left) represent examples belonging to Class 1. (Middle), are examples from Class 2. (Right) are examples from Class 3. (a) is from northwest Spain at $7.9^{\circ} \mathrm{W}$ and $42.8^{\circ} \mathrm{N}$. (b) represents central Colombia at $71.6^{\circ} \mathrm{W}$ and $5.0^{\circ} \mathrm{N}$. (c) was sampled at $94.4^{\circ} \mathrm{W} 42.0^{\circ} \mathrm{N}$ in Nebraska, in the United States. (d) is from northern Madagascar at $45.5^{\circ} \mathrm{E}$ and $17.5^{\circ} \mathrm{S}$. (e) was measured at $104.5^{\circ} \mathrm{W}$ and $49.5^{\circ} \mathrm{N}$ in southern Saskatchewan. (f) represents northern Alaska at $161.2^{\circ} \mathrm{W}$ and $69.9^{\circ} \mathrm{N}$.

Class 1

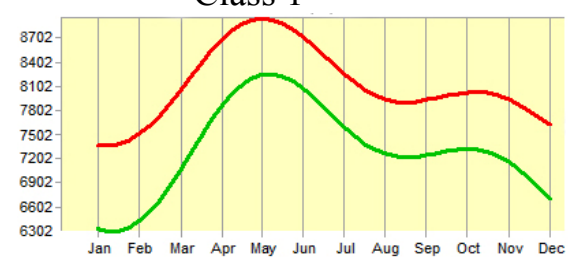

(a)

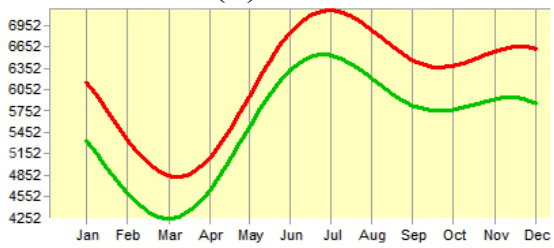

(d)

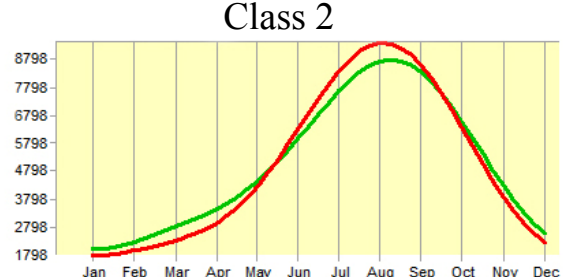

(b)

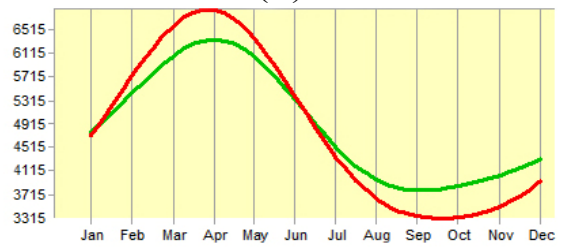

(e)

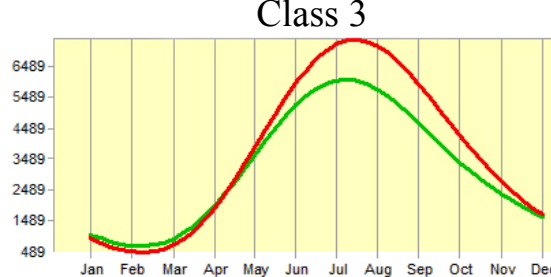

(c)

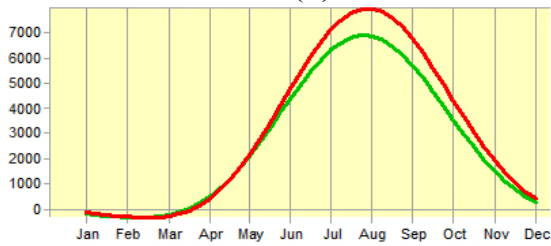

(f)

\section{Other Classes}

The remaining combination of trends in Amplitude 0, Amplitude 1, Amplitude 2, Phase 1 and Phase 2 encompass 223 classes that include positive, not significant, and negative trends in the different shape parameters. From these remaining classes, 78 correspond to significant increases in Amplitude 0, indicating a net increase in NDVI, and either positive, negative or not significant trends in the other four shape parameters. These 78 classes correspond to $29.14 \%$ of all changes $\left(16,765,653 \mathrm{~km}^{2}\right)$. Negative trends in mean annual NDVI (Amplitude 0) are also present (Figure S2), and are divided in 69 different classes, with negative trends in Amplitude 0 and either positive, negative or not significant trends in the other four shape parameters. However, these significant negative trends in NDVI, with an area of 2,107,636 $\mathrm{km}^{2}$ represent a small proportion of all changes $(3.66 \%)$, and are mainly distributed in the Chaco Ecoregion of South America and parts of the Boreal Forests/Taiga Biome.

\section{Discussion}

What is striking about these results is that not only do these three classes dominate seasonal trends, but also that they are associated with a strongly preferred distribution of biomes. Class 1 , the most prevalent, is clearly dominated by forests, and particularly broadleaf forests, followed by conifers. Class 2, on the other hand, is dominated by grasslands and shrublands, while Class 3 is predominantly 
found in the Tundra and Taiga biomes. Further, they are all more commonly associated with natural landscapes, suggesting that anthropogenic land cover conversion is not the primary agent of change in seasonality within these three classes.

Class 1, dominated by forests, exhibits a significant increase in mean annual NDVI without significant changes in any of the other shape parameters. This implies an increase in productivity year round and a lengthening of the growing season with both an earlier green-up and a later green-down.

Long term studies of phenological changes in Mediterranean vegetation have reported an advance of leaf-out and a delay of leaf abscission, and experimental studies have related these changes to warmer temperatures [48]. Many studies have also shown productivity increases in forested areas. For example, according to the analysis of European forests inventories and timber harvest statistics by Ciais et al. [49], the growth rate and the area of European forests increased between 1950 and 2000 leading to an increase in carbon accumulation in the region. Boisvenue and Running [50] provide additional ground and satellite-based evidence of productivity increases since 1950 in their review of the literature on climate change effects on forest productivity. Out of the 49 studies reviewed, 37 found positive trends. Their review included global and regional studies and mostly focused on the northern hemisphere and the Amazon region (where the bulk of Class 1 instances were located).

Studies focusing on forest systems attribute the increase in productivity to several factors such as global and regional warming, which promotes growth in temperature limited forests, $\mathrm{CO}_{2}$ fertilization, and nitrogen deposition [19,20,50,51]. Increased productivity over the Amazon and Europe has been attributed to radiation increase, largely associated with a decrease in cloudiness, and $\mathrm{CO}_{2}$ fertilization [50,51]. Changes in forest productivity have also been attributed to changes in land utilization such as decreased harvesting [49,52].

Class 2, dominated by grasslands and shrublands, exhibits significant increases in the annual amplitude of seasonality with no significant trend in any other parameter. Thus increasing NDVI in the green season is balanced by decreasing NDVI in the brown season. Several studies have noted an increasing trend in NDVI in grassland, shrubland and dryland areas [53-55]. However, since the majority of phenological studies focus only on the growing season, it has been difficult to corroborate the associated decline in brown season phenology associated with Class 2. This may be due in part, to the fact that measuring the end of the growing season is more challenging than the leaf out date in spring [22].

Although dominated by grasslands and shrublands, Class 2 is associated with biomes of substantially different climate characteristics. The Mountain Grassland and Shrublands Biome, is adapted to cool temperatures and intense sunlight with the majority of the areas under this biome experiencing a dry season and some having rainfall all year round. The Flooded Grasslands and Savannas Biome is limited by water, being flooded during the wet season and water stressed during the dry season. Other biomes that experience Class 2 seasonal changes have a characteristic dry season, and therefore water availability is the main factor limiting vegetation growth. The Tropical and Subtropical Grasslands, Savannas and Shrublands Biome is limited by an intense dry season [56]. This ecosystem (with C4 dominated grasslands [57]) is regulated by drought, where deciduous plants drop their leaves as a response to dryness (similar to temperate mid-latitudes where deciduousness is related to temperature), and the degree of leaf drop and herbaceous mortality during this season depends solely on soil moisture availability $[56,58]$. The Temperate Grasslands, Savannas and Shrublands 
Biome (with C3 dominated grasslands) corresponds to Dry Mid-latitude Steppe and Semidesert areas in which plant growth is limited by aridity (with soil moisture being deficient year round) and cold temperatures during the winter months [56]. The Tropical and Subtropical Coniferous Forest Biome, and the Tropical and Subtropical Dry Broadleaf Forest Biome also experience a high water deficit during a large part of the year. Although their characteristics vary substantially, what these biomes share is the presence of one or more substantial environmental limitations, most commonly related to water. The seasonal trend associated with these areas is such that NDVI (and by association, productivity) is enhanced during the green season and inhibited during the brown season.

Class 3, primarily associated with high latitude areas of the northern hemisphere, exhibits significant increases in both the mean annual NDVI and the annual amplitude in NDVI. As noted previously, this relates to an increase in productivity in the growing season with no effect on the brown season.

In the Taiga biome, primary production is limited by temperature [56]. There has been reported evidence of increased productivity in the Arctic region due to $\mathrm{CO}_{2}$ induced temperature increases $[19,59,60]$. However, increasing trends in productivity are not consistent in the Boreal forest $[50,60,61]$, and some authors argue that the observed responses may be related to the role of forest fires regulating productivity [62,63], with instances of increasing NDVI relating to forest re-growth [61].

In the Tundra Biome, vegetation growth is constrained by temperature and ground snow cover. Plant growth is activated only when soils have thawed, and therefore the growing season depends on the depth of snow cover [56]. Seasonal changes in the Tundra biome can be consistently linked to temperature increases and the impacts of climate change on the composition and structure of vegetation. There is evidence of large declines in snow cover duration in the Boreal forest and Tundra Biomes during the 20th century in relation to increases in temperature [64-66], which extends the period of time of plant photosynthetic activity. Moreover, several observational and experimental studies have reported a linkage between climate change and the modification of the structure of plant communities in the Arctic [67,68], particularly increases in shrub cover [68-73] with declines of lichens, moss and forbs $[67,68,70,74]$, which have been related to increases in summer temperature and nutrient availability $[68,73,75]$ and may have contributed to the increase in primary productivity in this biome $[69,76]$.

It should also be noted that a small, but noticeable percentage of Class 3 , is found in the grassland/shrubland areas of the Sahel. This trend is similar in effect in that it is located in areas that exhibit increasing productivity in the green season. During the period measured (1982-2011) there has been a marked increase in precipitation in this region with a well-documented greening [77,78]. Thus while the causes are very different from high latitude areas, the effect on greening is the same.

Finally, it is important to note several issues about these results. First, while these are long term trends over the 30 year period examined, there is no assurance that they are not transient or oscillatory. For example, short-term variability in the NAO will have been effectively removed by the procedure used in this study, but low frequency oscillations on the order of decades may still underlie the trends observed. Furthermore, while this study focuses on overall trends, we note that there is variability of the trends in NDVI over space and time. This variability has been documented by studies at different spatial and/or temporal scales emphasizing the need for longer NDVI series, ground validation, and 
cross validation of NDVI series between sensors [22,79], as well as the examination of discrepancies in the results obtained applying different methodologies [80].

Second, with an 8-km pixel resolution, land cover contributions are inevitably mixed. Thus the trends observed may be as much related to land cover changes as they are to true phenological responses. While the majority of the trends observed were determined not to be associated with anthropogenic land conversion, a substantial number are, and non-anthropogenic land cover changes may be involved, such as was noted in the Arctic.

Third, the approach taken in this paper represents an important extension of the STA procedure. The STA technique introduced in [18] was intended for the examination of seasonal trends in specific locations. In this paper we have extended the technique to focus on families (classes) of curves with similar trends in shape parameters through categorization based on statistical significance using the Contextual Mann-Kendall procedure.

Fourth, it should be noted that the results are based on the GIMMS NDVI3g dataset in its original form, without further corrections. Our preprocessing consisted of the aggregation of bi-monthly to monthly data only. The dataset used here has already been corrected for orbital drift effects, stratospheric volcanic aerosols, and other artifacts [24,81]. It relates well to vegetation productivity and climate, and it is highly correlated with MODIS NDVI, supporting its use for the study of long term vegetation changes [81]. Due to its recent development, we have not found any comprehensive evaluation of the quality of this dataset identifying issues that may have impacted our analysis, but we recognize that further investigations are needed in this respect.

\section{Conclusion}

Generalizing from these results, there are several broad conclusions that can be reached from this analysis of the 30-year NDVI record.

(1) Changes in seasonality are prevalent in the landscape. Over half of all land areas (56.30\%) are experiencing a significant trend in seasonality. Given the prevalence of cloud contamination and interannual variability which make the determination of statistical significance difficult, this is substantial.

(2) Of these significant trends, almost half are associated with just three classes of seasonal trends. The largest (Class 1) describes areas that are experiencing a uniform increase in NDVI throughout the year. The second largest, Class 2, shows increasing NDVI in the green season balanced by decreasing NDVI in the brown season. Class 3 is associated with increasing NDVI in the green season only.

(3) There is a strong biome association with these classes. Class 1 is primarily associated with forests, particularly broadleaf forests. Class 2 in primarily associated with grassland and shrubland biomes. Class 3 is most strongly associated with the high latitude regions of the northern hemisphere.

(4) While evidence of land conversion is present in all three classes, it is not their dominant driver.

(5) While supportive evidence was found to corroborate these trends, attribution of the trends is diverse. For Class 1, which exhibits uniform increases in NDVI, increases in temperature and decreases in cloudiness are prevalent attributions. Other possible causes cited include $\mathrm{CO}_{2}$ 
fertilization, nitrogen deposition and changes in land utilization. For Class 2, increased access to water during the growing season is the prevalent explanation. Class 3 would appear to be strongly associated with pronounced changes in climate. For the Taiga Biome, factors cited include temperature increases and fire dynamics, while for the Tundra, the most frequently cited attribution is warming temperatures. For the Sahel, the cited cause for the observed Class 3 trends is primarily increased precipitation. It would appear, then, that there is no single cause for these observed trends. However, it is reasonable to assert that they are predominantly related to a changing climate and that they have largely had an impact of ameliorating growing conditions during the period examined.

From this remarkable 30-year archive of satellite imagery, we thus see evidence of a greening trend. Monitoring the evolution of this will be an important task for the next 30 years of earth observation.

\section{Acknowledgments}

The authors wish to thank the NASA Global Inventory Modeling and Mapping Studies (GIMMS) group for producing and sharing the AVHRR GIMMS NDVI3g dataset. We also thank the Guest Editors, Ranga Myneni and Jorge Pinzón for inviting us to contribute to this special issue, and the four anonymous reviewers whose comments helped to improve the manuscript.

\section{Conflicts of Interest}

The authors declare no conflict of interest.

\section{References}

1. Menzel, A.; Fabian, P. Growing season extended in Europe. Nature 1999, 397, 659-659.

2. Hermance, J.F.; Jacob, R.W.; Bradley, B.A.; Mustard, J.F. Extracting phenological signals from multiyear AVHRR NDVI time series: Framework for applying high-order annual splines with roughness damping. IEEE Trans. Geosci. Remote Sens. 2007, 45, 3264-3276.

3. White, M.A.; de Beurs, K.M.; Didan, K.; Inouye, D.W.; Richardson, A.D.; Jensen, O.P.; O'Keefe, J.; Zhang, G.; Nemani, R.R.; van Leeuwen, W.J.D.; et al. Intercomparison, interpretation, and assessment of spring phenology in North America estimated from remote sensing for 1982-2006. Glob. Chang. Biol. 2009, 15, 2335-2359.

4. Abu-Asab, M.S.; Peterson, P.M.; Shetler, S.G.; Orli, S.S. Earlier plant flowering in spring as a response to global warming in the Washington, DC, area. Biodivers. Conserv. 2001, 10, 597-612.

5. Peñuelas, J.; Filella, I.; Comas, P. Changed plant and animal life cycles from 1952 to 2000 in the Mediterranean region. Glob. Chang. Biol. 2002, 8, 531-544.

6. Walther, G.; Post, E.; Convey, P.; Menzel, A.; Parmesan, C.; Beebee, T.J.C.; Fromentin, J.; Hoegh-Guldberg, O.; Bairlein, F. Ecological responses to recent climate change. Nature 2002, 416, 389-395.

7. Hegland, S.J.; Nielsen, A.; Lázaro, A.; Bjerknes, A.L.; Totland, Ø. How does climate warming affect plant-pollinator interactions? Ecol. Lett. 2009, 12, 184-195. 
8. Pettorelli, N.; Vik, J.O; Mysterud, A.; Gaillard, J.M.; Tucker, C.J.; Stenseth, N.C. Using the satellite-derived NDVI to assess ecological responses to environmental change. Trends Ecol. Evol. 2005, 20, 503-510.

9. Bartomeus, I.; Ascher, J.S.; Wagner, D.; Danforth, B.N.; Colla, S.; Kornbluth, S.; Winfree, R. Climate-associated phenological advances in bee pollinators and bee-pollinated plants. Proc. Natl. Acad. Sci. USA 2011, 108, 20645-20649.

10. Visser, M.; van Noordwijk, A.; Tinbergen, J.; Lessells, C. Warmer springs lead to mistimed reproduction in great tits (Parus major). Proc. R. Soc. Lond. B Biol. 1998, 265, 1867-1870.

11. Møller, A.P.; Rubolini, D.; Lehikoinen, E. Populations of migratory bird species that did not show a phenological response to climate change are declining. Proc. Natl. Acad. Sci. USA 2008, 105, $16195-16200$.

12. Rouse, J.W., Jr.; Haas, R.H.; Deering, D.W.; Schell, J.A.; Harlan, J.C. Monitoring the Vernal Advancement and Retrogradation (Green Wave Effect) of Natural Vegetation; NASA/GSFC: Greenbelt, MD, USA, 1974.

13. Tucker, C.J. Red and photographic infrared linear combinations for monitoring vegetation. Remote Sens. Environ. 1979, 8, 127-150.

14. Goward, S.N.; Tucker, C.J.; Dye, D.G. North American vegetation patterns observed with the NOAA-7 advanced very high resolution radiometer. Vegetatio 1985, 64, 3-14.

15. Myneni, R.B.; Hall, F.G.; Sellers, P.J.; Marshak, A.L. The interpretation of spectral vegetation indexes. IEEE Trans. Geosci. Remote Sens. 1995, 33, 481-486.

16. Ollinger, S. Sources of variability in canopy reflectance and the convergent properties of plants. New Phytol. 2011, 189, 375-394.

17. Holben, B.N. Characteristics of maximum-value composite images from temporal AVHRR data. Int. J. Remote Sens. 1986, 7, 1417-1434.

18. Eastman, J.R.; Sangermano, F.; Ghimire, B.; Zhu, H.; Chen, H.; Neeti, N.; Cai, Y.; Machado, E.A.; Crema, S.C. Seasonal trend analysis of image time series. Int. J. Remote Sens. 2009, 30, 2721-2726.

19. Myneni, R.B.; Keeling, C.; Tucker, C.; Asrar, G.; Nemani, R. Increased plant growth in the northern high latitudes from 1981 to 1991. Nature 1997, 386, 698-702.

20. Zhou, L.; Tucker, C.J.; Kaufmann, R.K.; Slayback, D.; Shabanov, N.V.; Myneni, R.B. Variations in northern vegetation activity inferred from satellite data of vegetation index during 1981 to 1999. J. Geophys. Res.-Atmos. 2001, 106, 20069-20083.

21. Sobrino, J.A.; Julien, Y. Global trends in NDVI-derived parameters obtained from GIMMS data. Int. J. Remote Sens. 2011, 32, 4267-4279.

22. Stöckli, R.; Vidale, P.L. European plant phenology and climate as seen in a 20-year AVHRR land-surface parameter dataset. Int. J. Remote Sens. 2004, 25, 3303-3330.

23. Pinzón, J.; Brown, M.E.; Tucker, C.J. EMD Correction of Orbital Drift Artifacts in Satellite Data Stream. In The Hilbert-Huang Transform and Its Applications; Huang, N., Shen, S., Eds.; World Scientific Publishing: Singapore, 2005; pp. 167-183.

24. Tucker, C.J.; Pinzón, J.E.; Brown, M.E.; Slayback, D.A.; Pak, E.W.; Mahoney, R.; Vermote, E.F.; El Saleous, N. An extended AVHRR 8-km NDVI dataset compatible with MODIS and SPOT vegetation NDVI data. Int. J. Remote Sens. 2005, 26, 4485-4498. 
25. Tucker, C.J.; Goff, T.; Townshend, J. African land-cover classification using satellite data. Science 1985, 227, 369-375.

26. Huete, A.R.; Tucker, C.J. Investigation of soil influences in AVHRR red and near-infrared vegetation index imagery. Int. J. Remote Sens. 1991, 12, 1223-1242.

27. Karnieli, A.; Shachak, M.; Tsoar, H.; Zaady, E.; Kaufman, Y.; Danin, A.; Porter, W. The effect of microphytes on the spectral reflectance of vegetation in semiarid regions. Remote Sens. Environ. 1996, 57, 88-96.

28. Lu, H.; Raupach, M.R.; McVicar, T.R.; Barrett, D.J. Decomposition of vegetation cover into woody and herbaceous components using AVHRR NDVI time series. Remote Sens. Environ. 2003, 86, 1-18.

29. Montandon, L.; Small, E. The impact of soil reflectance on the quantification of the green vegetation fraction from NDVI. Remote Sens. Environ. 2008, 112, 1835-1845.

30. Jeong, S.J.; Ho, C.H.; Brown, M.E.; Kug, J.S.; Piao, S. Browning in desert boundaries in Asia in recent decades. J. Geophys. Res.-Atmos. 2011, 116, 1984-2012.

31. Olson, D.M.; Dinerstein, E.; Wikramanayake, E.D.; Burgess, N.D.; Powell, G.V.; Underwood, E.C.; D'amico, J.A.; Itoua, I.; Strand, H.E.; Morrison, J.C. Terrestrial ecoregions of the world: A new map of life on earth: A new global map of terrestrial ecoregions provides an innovative tool for conserving biodiversity. Bioscience 2001, 51, 933-938.

32. Bontemps, S.; Defourny, P.; van Bogaert, E.; Arino, O.; Kalogirou, V.; Perez, J.R. GlobCover 2009: Products Description and Validation Report; European Spatial Agency and Université Catholique de Louvain: Frascati, Italy, 2011. Available online: http://due.esrin.esa.int/globcover/ LandCover2009/GLOBCOVER2009_Validation_Report_2.2.pdf (accessed on 3 July 2013).

33. Torrence, C.; Compo, G.P. A practical guide to wavelet analysis. Bull. Am. Meteorol. Soc. 1998, 79, 61-78.

34. Madden, R.A.; Julian, P.R. Detection of a 40-50 day oscillation in the zonal wind in the tropical Pacific. J. Atmos. Sci. 1971, 28, 702-708.

35. Hoaglin, D.C.; Mosteller, F.; Tukey, J.W. Understanding Robust and Exploratory Data Analysis; Wiley: New York, NY, USA, 2000; Volume 3.

36. Eastman, J.R. IDRISI 16: The Taiga Edition; Clark Univeristy: Worcester, MA, USA, 2009.

37. Henebry, G.M.; Betancourt, J.L. Toward a US National Phenological Assessment. EOS Trans. $A G U$ 2009, 91, 3.

38. Richardson, A.D.; Braswell, B.H.; Hollinger, D.Y.; Jenkins, J.P.; Ollinger, S.V. Near-surface remote sensing of spatial and temporal variation in canopy phenology. Ecol. Appl. 2009, 19, 1417-1428.

39. De Beurs, K.M.; Henebry, G.M. Spatio-Temporal Statistical Methods for Modelling Land Surface Phenology. In Phenological Research; Springer: New York, NY, USA, 2010; pp. 177-208.

40. Reed, B.C.; Brown, J.F.; VanderZee, D.; Loveland, T.R.; Merchant, J.W.; Ohlen, D.O. Measuring phenological variability from satellite imagery. J. Veg. Sci. 1994, 5, 703-714.

41. Gilmanov, T.G.; Tieszen, L.L.; Wylie, B.K.; Flanagan, L.B.; Frank, A.B.; Haferkamp, M.R.; Meyers, T.P.; Morgan, J.A. Integration of $\mathrm{CO}_{2}$ flux and remotely-sensed data for primary production and ecosystem respiration analyses in the Northern Great Plains: Potential for quantitative spatial extrapolation. Glob. Ecol. Biogeogr. 2005, 14, 271-292. 
42. Wylie, B.K.; Johnson, D.A.; Laca, E.; Saliendra, N.Z.; Gilmanov, T.G.; Reed, B.C.; Tieszen, L.L.; Worstell, B.B. Calibration of remotely sensed, coarse resolution NDVI to $\mathrm{CO}_{2}$ fluxes in a sagebrush-steppe ecosystem. Remote Sens. Environ. 2003, 85, 243-255.

43. Linderman, M.; Rowhani, P.; Benz, D.; Serneels, S.; Lambin, E.F. Land-cover change and vegetation dynamics across Africa. J. Geophys. Res.-Atmos. 2005, 110, D12104.

44. Neeti, N.; Eastman, J.R. A contextual mann-kendall approach for the assessment of trend significance in image time series. Trans. GIS 2011, 15, 599-611.

45. Mann, H.B. Nonparametric tests against trend. Econometrica 1945, 13, 245-259.

46. Kendall, M.G. Rank Correlation Methods; Charles Griffin: London, UK, 1975.

47. Abdi, H. Bonferroni and Šidák Corrections for Multiple Comparisons. In Encyclopedia of Measurement and Statistics; Salkind, N., Ed.; SAGE: Thousand Oaks, CA, USA, 2007.

48. Richardson, A.D.; Keenan, T.F.; Migliavacca, M.; Ryu, Y.; Sonnentag, O.; Toomey, M. Climate change, phenology, and phenological control of vegetation feedbacks to the climate system. Agric. For. Meteorol. 2013, 169, 156-173.

49. Ciais, P.; Schelhaas, M.; Zaehle, S.; Piao, S.; Cescatti, A.; Liski, J.; Luyssaert, S.; Le-Maire, G.; Schulze, E.-D.; Bouriaud, O. Carbon accumulation in European forests. Nat. Geosci. 2008, 1, 425-429.

50. Boisvenue, C.; Running, S.W. Impacts of climate change on natural forest productivity-Evidence since the middle of the 20th century. Glob. Chang. Biol. 2006, 12, 862-882.

51. Nemani, R.R.; Keeling, C.D.; Hashimoto, H.; Jolly, W.M.; Piper, S.C.; Tucker, C.J.; Myneni, R.B.; Running, S.W. Climate-driven increases in global terrestrial net primary production from 1982 to 1999. Science 2003, 300, 1560-1563.

52. Nabuurs, G.J.; Pussinen, A.; Karjalainen, T.; Erhard, M.; Kramer, K. Stemwood volume increment changes in European forests due to climate change-A simulation study with the EFISCEN model. Glob. Chang. Biol. 2002, 8, 304-316.

53. Piao, S.; Mohammat, A.; Fang, J.; Cai, Q.; Feng, J. NDVI-based increase in growth of temperate grasslands and its responses to climate changes in China. Glob. Environ. Chang. 2006, $16,340-348$.

54. Fensholt, R.; Langanke, T.; Rasmussen, K.; Reenberg, A.; Prince, S.D.; Tucker, C.; Scholes, R.J.; Le, Q.B.; Bondeau, A.; Eastman, R.; et al. Greenness in semi-arid areas across the globe 1981-2007-An Earth Observing Satellite based analysis of trends and drivers. Remote Sens. Environ. 2012, 121, 144-158.

55. Zhao, X.; Zhou, D.; Fang, J. Satellite-based studies on large-scale vegetation changes in China. J. Integr. Plant Biol. 2012, 54, 713-728.

56. Schultz, J. The Ecozones of the World: The Ecological Divisions of the Geosphere, 2nd ed.; Springer: New York, NY, USA, 2005.

57. Collatz, G.J.; Berry, J.A.; Clark, J.S. Effects of climate and atmospheric $\mathrm{CO}_{2}$ partial pressure on the global distribution of C4 grasses: Present, past, and future. Oecologia 1998, 114, 441-454.

58. D’Odorico, P.; Porporato, A. Dryland Ecohydrology; Springer: Dordrecht, The Netherlands, 2006.

59. Chapin, F.S., III; Eugster, W.; McFadden, J.P.; Lynch, A.H.; Walker, D.A. Summer differences among arctic ecosystems in regional climate forcing. J. Clim. 2000, 13, 2002-2010. 
60. Goetz, S.J.; Bunn, A.G.; Fiske, G.J.; Houghton, R. Satellite-observed photosynthetic trends across boreal North America associated with climate and fire disturbance. Proc. Natl. Acad. Sci. USA 2005, 102, 13521-13525.

61. Goetz, S.; Mack, M.; Gurney, K.; Randerson, J.; Houghton, R. Ecosystem responses to recent climate change and fire disturbance at northern high latitudes: Observations and model results contrasting Northern Eurasia and North America. Environ. Res. Lett. 2007, 2, 045031.

62. Furyaev, V.; Vaganov, E.A.; Tchebakova, N.M.; Valendik, E.N. Effects of fire and climate on successions and structural changes in the Siberian boreal forest. Eurasian J. For. Res. 2001, 2 , $1-15$.

63. Soja, A.J.; Tchebakova, N.M.; French, N.H.; Flannigan, M.D.; Shugart, H.H.; Stocks, B.J.; Sukhinin, A.I.; Parfenova, E.; Chapin, F.S., III; Stackhouse, P.W., Jr. Climate-induced boreal forest change: Predictions versus current observations. Glob. Planet. Chang. 2007, 56, 274-296.

64. Brown, R.D. Northern hemisphere snow cover variability and change, 1915-97. J. Clim. 2000, 13, 2339-2355.

65. Chapin, F.S., III; Sturm, M.; Serreze, M.; McFadden, J.; Key, J.; Lloyd, A.; McGuire, A.; Rupp, T.; Lynch, A.; Schimel, J. Role of land-surface changes in Arctic summer warming. Science 2005, 310, 657-660.

66. Euskirchen, E.; McGuire, A.; Chapin, F.S., III. Energy feedbacks of northern high-latitude ecosystems to the climate system due to reduced snow cover during 20th century warming. Glob. Chang. Biol. 2007, 13, 2425-2438.

67. Hollister, R.D.; Webber, P.J.; Tweedie, C.E. The response of Alaskan arctic tundra to experimental warming: Differences between short-and long-term responses. Glob. Chang. Biol. 2005, 11, 525-536.

68. Walker, M.D.; Wahren, C.H.; Hollister, R.D.; Henry, G.H.; Ahlquist, L.E.; Alatalo, J.M.; Bret-Harte, M.S.; Calef, M.P.; Callaghan, T.V.; Carroll, A.B. Plant community responses to experimental warming across the tundra biome. Proc. Natl. Acad. Sci. USA 2006, 103, $1342-1346$.

69. Sturm, M.; Racine, C.; Tape, K. Climate change: Increasing shrub abundance in the Arctic. Nature 2001, 411, 546-547.

70. Epstein, H.E.; Calef, M.P.; Walker, M.D.; Stuart Chapin, F.; Starfield, A.M. Detecting changes in arctic tundra plant communities in response to warming over decadal time scales. Glob. Chang. Biol. 2004, 10, 1325-1334.

71. Tape, K.; Sturm, M.; Racine, C. The evidence for shrub expansion in northern Alaska and the Pan-Arctic. Glob. Chang. Biol. 2006, 12, 686-702.

72. Hudson, J.; Henry, G. Increased plant biomass in a High Arctic heath community from 1981 to 2008. Ecology 2009, 90, 2657-2663.

73. Hallinger, M.; Manthey, M.; Wilmking, M. Establishing a missing link: Warm summers and winter snow cover promote shrub expansion into alpine tundra in Scandinavia. New Phytol. 2010, 186, 890-899.

74. Chapin, F.S., III; Shaver, G.R.; Giblin, A.E.; Nadelhoffer, K.J.; Laundre, J.A. Responses of Arctic tundra to experimental and observed changes in climate. Ecology 1995, 76, 694-711. 
75. Bret-Harte, M.S.; Shaver, G.R.; Chapin, F.S. Primary and secondary stem growth in arctic shrubs: Implications for community response to environmental change. J. Ecol. 2002, 90, 251-267.

76. Jia, G.J.; Epstein, H.E.; Walker, D.A. Greening of arctic Alaska, 1981-2001. Geophys. Res. Lett. 2003, 30, 2067.

77. Eklundh, L.; Olsson, L. Vegetation index trends for the African Sahel 1982-1999. Geophys. Res. Lett. 2003, 30, 1430.

78. Herrmann, S.M.; Anyamba, A.; Tucker, C.J. Recent trends in vegetation dynamics in the African Sahel and their relationship to climate. Glob. Environ. Chang. 2005, 15, 394-404.

79. Delbart, N.; Picard, G.; le Toan, T.; Kergoat, L.; Quegan, S.; Woodward, I.; Dye, D.; Fedotova, V. Spring phenology in boreal Eurasia over a nearly century time scale. Glob. Chang. Biol. 2008, 14, 603-614.

80. De Jong, R.; de Bruin, S.; de Wit, A.; Schaepman, M.E.; Dent, D.L. Analysis of monotonic greening and browning trends from global NDVI time-series. Remote Sens. Environ. 2011, 115, 692-702.

81. Zeng, F.-W.; Collatz, G.J.; Pinzon, J.E.; Ivanoff, A. Evaluating and quantifying the climate-driven interannual variability in Global Inventory Modeling and Mapping Studies (GIMMS) Normalized Difference Vegetation Index (NDVI3g) at global scales. Remote Sens. 2013, 5, 3918-3950.

(C) 2013 by the authors; licensee MDPI, Basel, Switzerland. This article is an open access article distributed under the terms and conditions of the Creative Commons Attribution license (http://creativecommons.org/licenses/by/3.0/). 